\title{
Visual outcomes and patient satisfaction 1 and 12 months after combined implantation of extended depth of focus and trifocal intraocular lenses
}

\author{
Richard N. McNeely $\cdot$ Salissou Moutari $\cdot$ Stephen Stewart · Jonathan E. Moore $\mathbb{D}$
}

Received: 15 April 2021 / Accepted: 16 July 2021 / Published online: 21 September 2021

(C) The Author(s) 2021

\begin{abstract}
Purpose To assess the 1-month and 12-month postoperative visual performance and subjective outcomes following combined implantation of an extended depth of focus (EDOF) intraocular lens (IOL) and a trifocal IOL.

Methods The study enrolled consecutive patients undergoing refractive lens extraction or cataract surgery with combined implantation of an EDOF IOL (dominant eye) and trifocal IOL. Uncorrected (UDVA) and best-corrected (CDVA) distance visual acuities, uncorrected intermediate (UIVA) and near (UNVA) visual acuities, and subjective questionnaires were evaluated 1 month and 12 months postoperatively.
\end{abstract}

R. N. McNeely · S. Stewart · J. E. Moore $(\square)$

Cathedral Eye Clinic, 89-91 Academy Street,

Belfast BT1 2 LS, Northern Ireland, UK

e-mail: johnny@cathedraleye.com

S. Moutari

School of Mathematics and Physics, Queens University

Belfast, Belfast, Northern Ireland, UK

J. E. Moore

Biomedical Sciences Research Institute, University of

Ulster, Coleraine, Northern Ireland, UK

J. E. Moore

Tianjin Medical University, Tianjin, China

J. E. Moore

Aston University, Birmingham, UK
Results The study enrolled 58 consecutive patients. Binocular UDVA, UIVA and UNVA were $-0.08 \pm 0.07 \log$ MAR, $0.15 \pm 0.14 \log$ MAR and $0.17 \pm 0.11 \log$ MAR at 1 month, compared to $-0.09 \pm 0.06 \quad \log$ MAR $(P=.323), 0.11 \pm 0.10$ $\log$ MAR $\quad(P=.030)$ and $0.13 \pm 0.10 \quad \log$ MAR $(P=0.008)$ at 12 months. Satisfaction was high with $93.1 \%$ of patients fulfilled or more than fulfilled postoperatively, and $84.5 \%$ and $86.3 \%$ reported spectacle independence for near at the respective postoperative assessments. The mean daytime and nighttime quality of vision $(\mathrm{QoV})$ scores were $9.12 \pm 0.94$ and $7.88 \pm 1.74$ at 1 month, compared to $9.24 \pm 0.78$ $(P=.183)$ and $8.26 \pm 1.38(P=.043)$ at 12 months. Conclusions This IOL combination provides good unaided visual acuity at 1 and 12 months postoperatively, with high functional vision and postoperative satisfaction reported at 1 and 12 months. However, a significant improvement in overall nighttime QoV at the 12 months assessment was found.

Keywords Quality of vision · Cataract surgery · Refractive lens exchange - Visual outcomes . Extended depth of focus IOL · Trifocal IOL 


\section{Introduction}

Various methodologies have been introduced in modern day lens-based surgery to provide a range of clear vision [1-6] with the least amount of visual side effects. Our recent study [7] sought to outline the clinical and patient-reported outcomes at an early postoperative period of the latest extended depth of focus (EDOF) technology, thought to provide superior intermediate vision with fewer unwanted visual phenomena, implanted in combination with a trifocal intraocular lens (IOL). The EDOF IOL was used in the dominant eye to provide good distance, intermediate and improve near vision and produce fewer unwanted visual phenomena, with the trifocal IOL implanted in the nondominant eye to provide adequate reading vision. This recent study [7] reported that the combination of an EDOF and trifocal IOL provides good unaided visual acuity for distance, and near distances, providing high postoperative satisfaction and functional vision, at an early postoperative stage. This current study sought to outline the objective visual and refractive outcomes, and patient satisfaction of this IOL combination in a cohort of patients at a longer postoperative period of 1 year, and to determine whether the objective and subjective outcomes altered over this postoperative period.

\section{Methods}

This retrospective study recruited patients who received a combined implantation of an EDOF IOL and a trifocal IOL following refractive lens exchange or cataract surgery between March 2018 and March 2019.

Consecutive patients were enrolled in this study with each patient giving their informed consent to undergo refractive lens exchange or cataract surgery prior to surgery, and for their unidentifiable patient data to be used for audit and publication.

The exclusion criteria for this study were any neuro-ophthalmic disease, corneal surgery or disease, ocular inflammation, a history of retinal detachment or glaucoma and macular disease. Preoperative corneal astigmatism of 1.50 diopters $(D)$ or less, no previous refractive surgery and the absence of any other ocular pathology were required with each patient for inclusion in this current study. Patients who developed visually significant posterior capsular opacification (PCO) and who had not yet received neodymium:yttrium-aluminum-garnet (Nd:YAG) at their 1 year assessment were also excluded.

All patients received full ophthalmological assessment preoperatively. Uncorrected (UDVA) and corrected (CDVA) distance visual acuities were evaluated with logarithmic acuity (logMAR) charts, and uncorrected intermediate (UIVA) and near (UNVA) visual acuities were evaluated with Radner reading charts $(70 \mathrm{~cm}$ and $40 \mathrm{~cm}$ ). Slit-lamp examination, Goldmann tonometry, and dilated funduscopy were completed. Additionally, stereopsis (TNO stereo test), corneal topography (OPD-Scan II; NIDEK Co., Ltd., Gamagori, Japan), corneal tomography (Pentacam, Oculus Optikgeäte $\mathrm{GmbH}$ ) and retinal optical coherence tomography (Cirrus 4000 OCT; Carl Zeiss Meditec) were completed. Biometry was completed with the Aladdin (Topcon). For each case the SRK/T, Haigis, HofferQ and Barrett Universal II were compared, and a decision made regarding the IOL power. To determine ocular dominance, the pointing methodology was utilized. Patients were asked to visually align their finger with a spot light source at $6 \mathrm{~m}$ with each eye then occluded. Ocular dominance was determined as the eye showing the smallest separation between the finger and the light source. Patients were also asked which eye they would use for sighting a camera and a rifle. The results from both ocular dominance assessments were required to be consistent to confirm ocular dominance. In the presence of significantly reduced vision due to cataract, the eye with the most severe cataract was operated on first.

Patients were examined 1 month and 12 months postoperatively. These assessments included manifest refraction, UDVA, CDVA, UIVA and UNVA. Patients also completed a purpose developed quality of vision (QoV) questionnaire as previously outlined [7]. This questionnaire utilizes pictures to aid understanding of the questions and patients report their responses on a Likert scale. To gain a better overall understanding of each patients' overall satisfaction, patients were asked to rate their day and night QoV on a linear 0 to 10 scale. A purpose-developed satisfaction questionnaire was also utilized where patients report their satisfaction regarding their distance, intermediate and near vision, and their overall vision, as outlined previously [7]. 
Intraocular lens

The AT LARA 829MP IOL (AT LARA 829MP; Carl Zeiss Meditec, Jena, Germany) is an EDOF IOL made from hydrophilic acrylic with hydrophobic surface properties and has a $6 \mathrm{~mm}$ optic size and a $11 \mathrm{~mm}$ overall length. The IOL is an aspheric lens based on a diffractive principle with a chromatic aberrationcorrecting and aberration-neutral optical design. There are two additions of $+0.95 \mathrm{D}$ and $+1.90 \mathrm{D}$ with a light bridge optical design and Smooth Microphase (SMP) technology to minimize light scattering. The available powers are -10.00 to $+32.00 \mathrm{D}$ in $0.50 \mathrm{D}$ increments.

The AT LISA tri 839MP IOL (AT LISA tri839MP; Carl Zeiss Meditec, Jena, Germany) is a diffractive trifocal IOL with $+1.66 \mathrm{D}$ and $+3.00 \mathrm{D}$ addition powers for intermediate and near vision. The IOL is made from hydrophilic acrylic with hydrophobic surface properties and has a $6 \mathrm{~mm}$ optic size and a $11 \mathrm{~mm}$ overall length. It is available in powers between 0.00 and $+32.00 \mathrm{D}$ in $0.50 \mathrm{D}$ increments.

Surgical technique

All surgeries were performed, under Sub-Tenon or topical anesthesia, by the same experienced surgeon (J.E.M). The first eye received an EDOF IOL in the dominant eye followed by the trifocal in the fellow eye one week later and emmetropia was the refractive aim in each case. Following phacoemulsification the IOL was inserted into the capsular bag through an incision of $2.75 \mathrm{~mm}$. A capsular tension ring was implanted in each case.

\section{Statistical analysis}

Statistical analysis was performed using SPSS for Windows (Statistical Package for the Social Sciences, Version 25, Chicago, Illinois, USA) and Excel (Microsoft; Redmond, Washington, USA). The preoperative and postoperative parameters were presented as means and standard deviations or percentages. The Kolmogorov-Smirnov test was used to assess normality. When assessing continuous normal data, the Student's paired $t$ test was used to compare postoperative data, and when assessing nonparametric data, the Wilcoxon rank-sum test was used. For all statistical analysis, the level of significance was $P<0.05$.

\section{Results}

This study included 116 eyes of 58 patients with a mean age of $59.0 \pm 7.0(44-81)$ years. Table 1 outlines the demographics and the preoperative clinical data.

Table 1 Demographics and clinical data

\begin{tabular}{lll}
\hline Parameter & Preoperative & AT LISA \\
\cline { 2 - 3 } & AT LARA & $58(58)$ \\
\hline No. of patients (eyes) & $58(58)$ & $59 \pm 7.0(44-81)$ \\
Age (y), mean \pm SD (range) & $19 / 39(32.8 / 67.2)$ & $23.59 \pm 1.17(20.98-27.35)$ \\
Gender, male / female (\%) & $9 / 49(15.5 / 84.5)$ & $21.51 \pm 3.97(7.0$ to 29.0$)$ \\
Myopia / hyperopia (\%) & $23.54 \pm 1.11(21.47-27.27)$ & $1.00 \pm 2.99(-12-5.25)$ \\
Axial length (mm), mean \pm SD (range) & $20.76 \pm 3.43(9.5$ to 27.5$)$ & $-0.54 \pm 0.52(-2.25-0)$ \\
Power of implanted IOL (D), mean \pm SD (range) & & $0.72 \pm 3.06(-12.63-4.50)$ \\
Clinical, mean \pm SD (range) & $0.88 \pm 2.77(-10-4.50)$ & $-0.02 \pm 0.20(-0.2-1.20)$ \\
Sphere (D) & $-0.48 \pm 0.45(-2-0)$ & $0.63 \pm 2.85(-10.63-3.88)$ \\
Cylinder (D) & $-0.01 \pm 0.28(-0.2-1.85)$ & \\
MSE (D) & & \\
CDVA & & \\
\hline SD stan & & \\
\hline
\end{tabular}

$\overline{\mathrm{SD}}=$ standard deviation; $\mathrm{IOL}=$ intraocular lens; $\mathrm{D}=$ diopters; $\mathrm{MSE}=$ manifest spherical equivalent; $\mathrm{CDVA}=$ corrected distance visual acuity 
Fig. 1 Cumulative binocular uncorrected a distance, $\mathbf{b}$ intermediate, and $\mathbf{c}$ near visual acuity 1 month and 12 months postoperatively.

(UDVA = uncorrected distance visual acuity; CDVA = uncorrected distance visual acuity) (a)

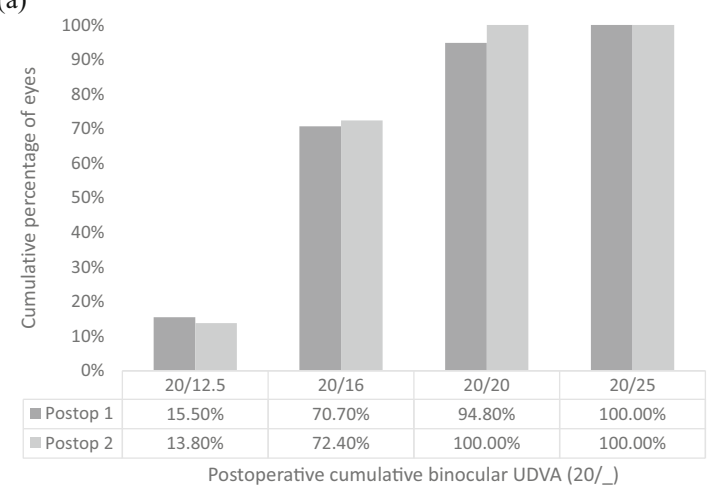

(b)

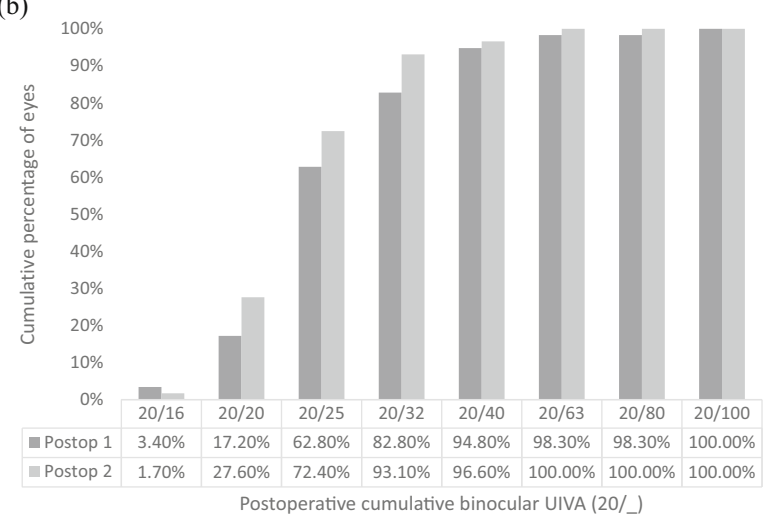

(c)

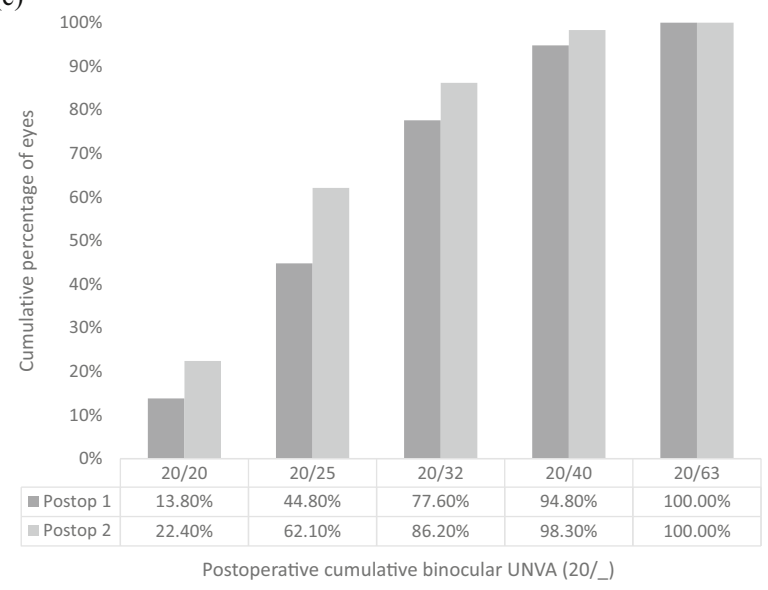

difference between the two postoperative assessments was found in binocular UIVA $(P=0.030)$ and UNVA $(P=0.008)$, with an improvement found at 12 months at both distances. Figure 2 shows the difference between the postoperative UDVA and CDVA at 1 and 12 months postoperatively for the EDOF and trifocal IOL eyes. Figure 3 displays the mean 


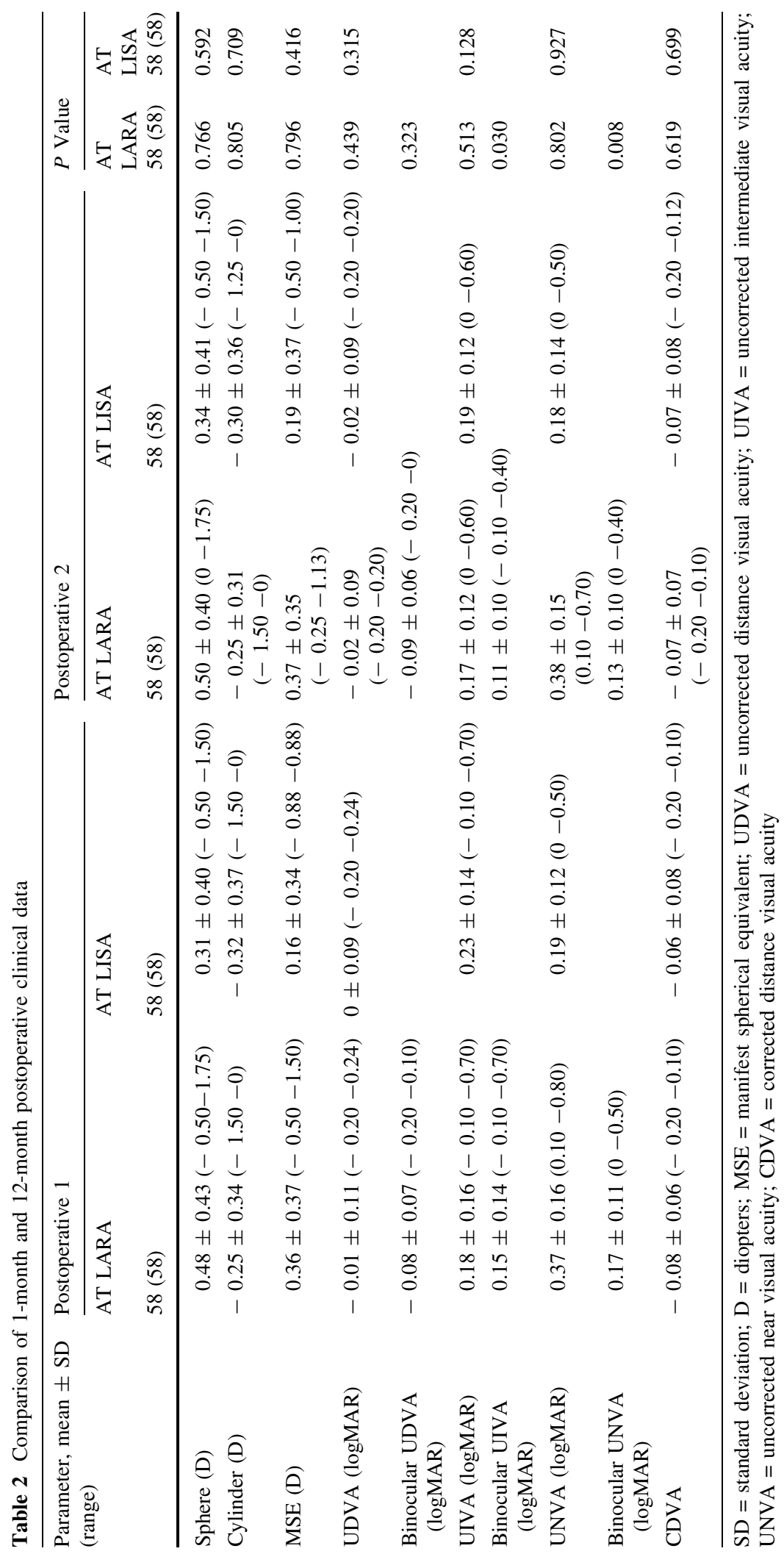


Fig. 2 Histogram showing the efficacy of lines of difference between postoperative UDVA and CDVA for a EDOF IOL and b trifocal IOL, at 1 month and 12 months postoperatively. (UDVA = uncorrected distance visual acuity, CDVA $=$ corrected distance visual acuity) (a)

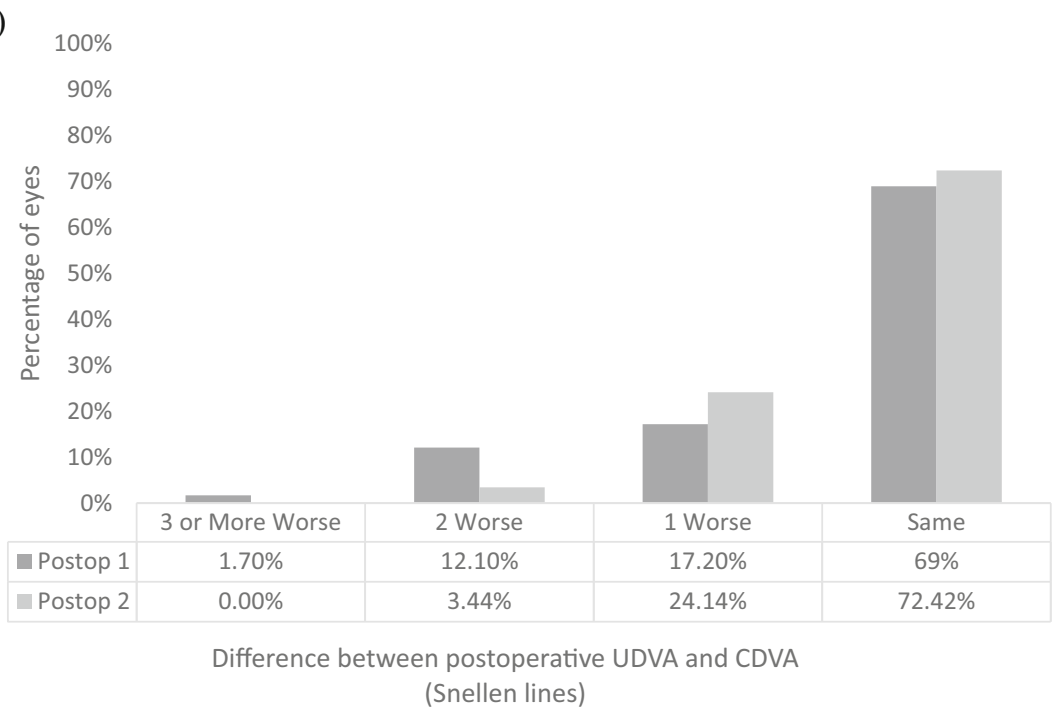

(b)

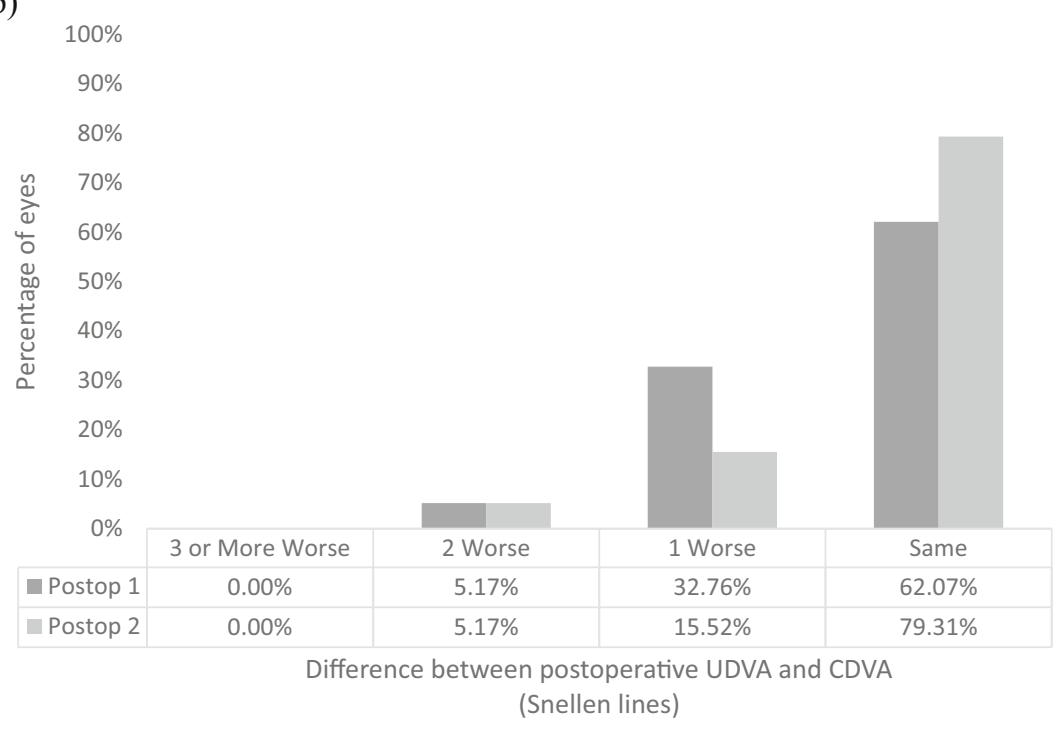

binocular defocus curve found at the first postoperative assessment.

Figure $4 \mathrm{a}$ shows the predictability for the EDOF IOLs. Postoperatively, 58.6\% of EDOF IOLs eyes were within $\pm 0.50 \mathrm{D}$ of the refractive target at 1 month and 12 months. One month postoperatively, $79.3 \%$ of trifocal IOLs were within $\pm 0.50 \mathrm{D}$, and $74.1 \%$ at 12 months (Fig. 4 b). Figure 5 outlines the postoperative refractive cylinder at both postoperative assessments for the respective IOL designs, where
$89.7 \%$ and $91.3 \%$ of EDOF IOL eyes had refractive cylinder of $0.5 \mathrm{D}$ or less at the two respective postoperative assessments, and $81 \%$ of trifocal IOL eyes at both postoperative assessments. There was no significant difference in mean refractive cylinder with both IOL designs (Table 2). Figure 6 shows the refractive stability of the spherical equivalent refraction up to 12 months postoperatively. Fifty-seven (98.3\%) EDOF IOL eyes and all trifocal IOL eyes had a change of spherical equivalent refraction of $1.00 \mathrm{D}$ 
Fig. 3 Binocular defocus curve at 1 month. $\mathrm{D}=$ diopters

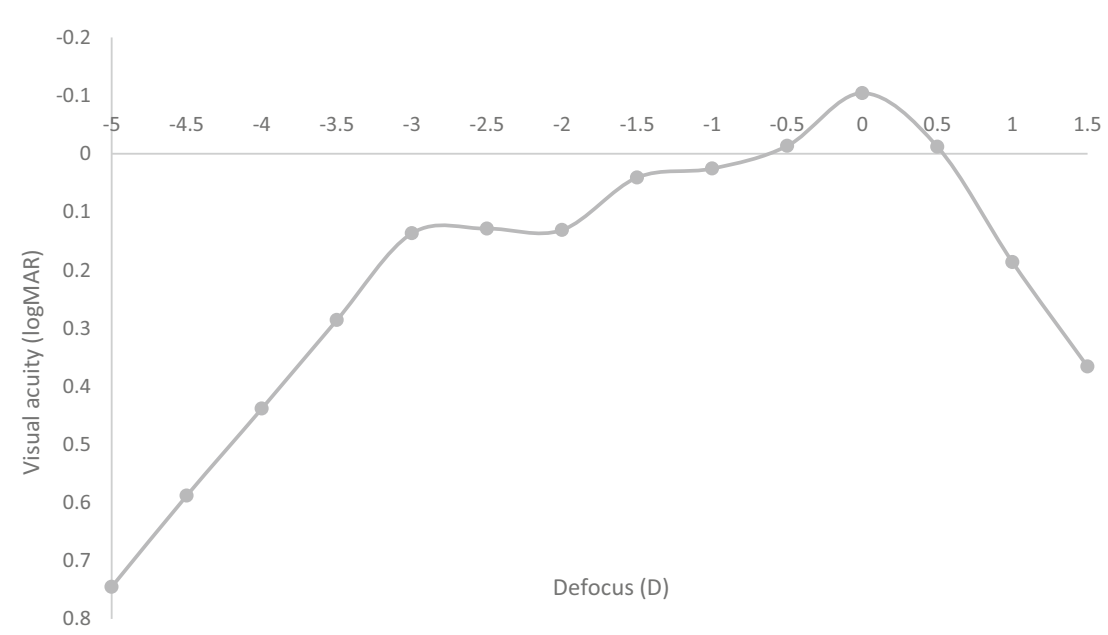

or less between 1 and 12 months postoperatively. Table 3 outlines how the postoperative refractive error changes between 1 and 12 months. With the EDOF and trifocal IOLs $75.7 \%$ and $58.9 \%$ of eyes changed less than $\pm 0.25 \mathrm{D}$ between the two postoperative assessments. For the EDOF IOL 13.8\% of eyes displayed a myopic shift of $>0.25 \mathrm{D}$ compared to $10.3 \%$ eyes having a hyperopic shift. With the trifocal IOL $16.1 \%$ of eyes had a myopic shift of $>0.25 \mathrm{D}$ compared to $25 \%$ showing a hyperopic shift.

\section{Patient-reported outcomes}

Table 4 outlines the responses from a patient satisfaction questionnaire, and Table 5 shows the subjective responses to visual disturbances and photopic phenomena at 1 and 12 months.

A significant improvement in overall nighttime QoV was found at 12 months when compared to the early postoperative assessment $(P=0.043)$.

\section{Complications}

Eight eyes (6.7\%) required neodymium:YAG (Nd:YAG) capsulotomy. Furthermore, two eyes implanted with a trifocal IOL required further laser enhancement with laser in situ keratomileusis (LASIK) for residual refractive error. No other adverse events occurred.

\section{Discussion}

Multifocal IOLs are well recognized as a method to provide high patient satisfaction and spectacle independence following cataract surgery or refractive lens exchange; however visual phenomena can be present postoperatively which can cause dissatisfaction [8,9], and in some cases an exchange of the IOL is required [10]. New designs of multifocal IOLs are continuing to be developed to optimize postoperative outcomes and reduced unwanted side effects. Our recent study outlined the early postoperative outcomes found after implantation of a new EDOF IOL in combination with a trifocal IOL [7]. This present study sought to determine the objective and subjective outcomes after this bilateral implantation of an EDOF IOL and a trifocal IOL up to a longer postoperative timepoint, and determine how these outcomes alter, if at all, over this postoperative period.

This IOL combination displayed excellent UDVA at both postoperative periods. The mean binocular UDVA was $-0.08 \pm 0.07 \log$ MAR at 1 month and $-0.09 \pm 0.06 \operatorname{logMAR}$ at 12 months, and no significant difference was found between the two postoperative periods (Table 2). This is superior to that found in the early postoperative outcomes following bilateral implantation of the new EDOF IOL [11], and that found in another study of the same implantation methodology 3 months postoperatively [12]. Furthermore, UDVA appears to be superior to that found in bilateral trifocal IOL implantation [13]. To our 
Fig. 4 Predictability for a EDOF IOL and $\mathbf{b}$ trifocal IOL, at 1 month and 12 months postoperatively. $(\mathrm{SE}=$ spherical equivalent; $\mathrm{D}=$ dioptres)

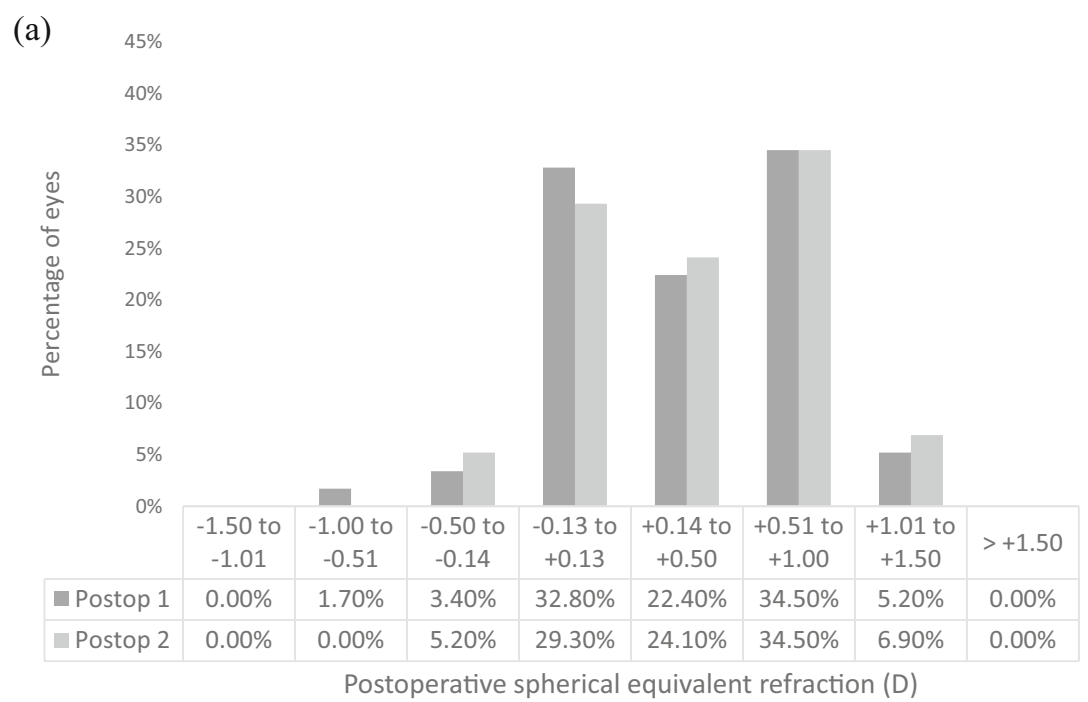

(b)

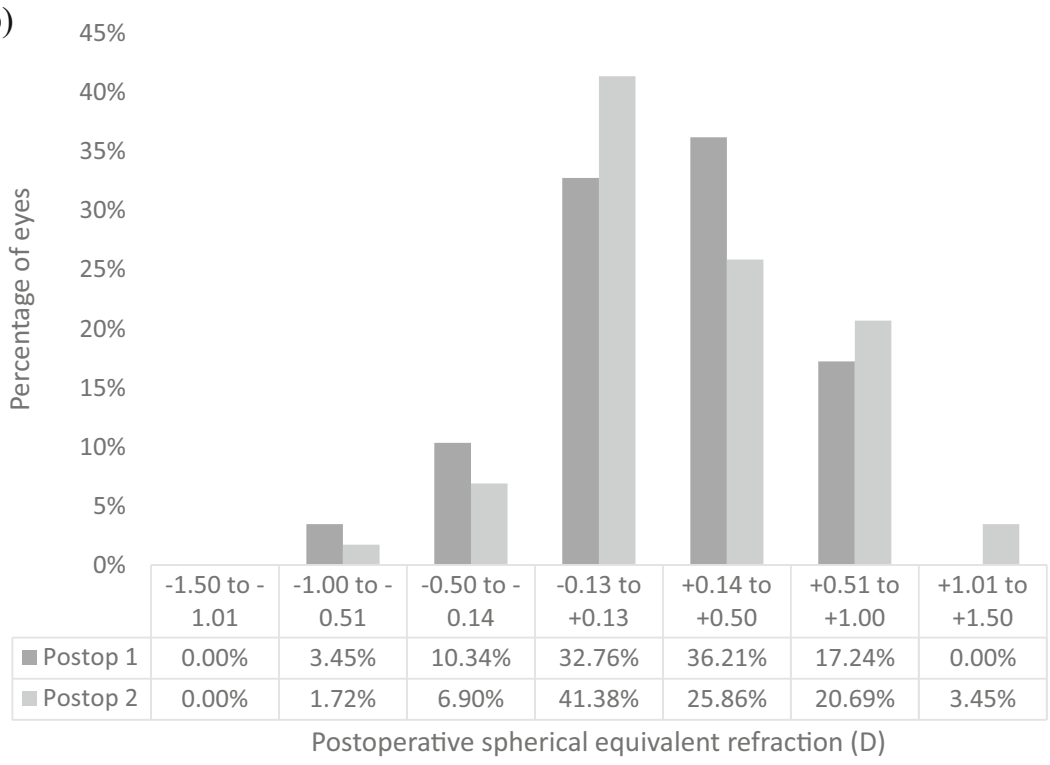

knowledge there is no study outlining the outcomes of this combination up to 1 year and this current study shows that the binocular UDVA remains stable throughout the first postoperative year.

The binocular UIVA results found were $0.15 \pm 0.14 \log$ MAR and $0.11 \pm 0.10 \log$ MAR at the two respective assessments (Table 2). The 1 month binocular UIVA is similar to that found in a study following bilateral implantation of a rotationally asymmetric multifocal IOL [14]. Similarly, this implantation methodology showed excellent binocular UNVA with a mean value of $0.17 \pm 0.11 \log$ MAR at 1 month and $0.13 \pm 0.10 \operatorname{logMAR}$ at 12 months, which appears to be superior to that found in bilateral implantation of trifocal IOLs [15], and bilateral EDOF IOLs $[11,16]$, however similar to that found in a study of rotationally asymmetric multifocal IOLs [17]. Both the binocular UIVA and UNVA showed significantly better outcomes at 12 months when compared to the early postoperative assessment. However, the 
Fig. 5 Postoperative refractive cylinder for a EDOF IOL and $\mathbf{b}$ trifocal IOL, at 1 month and 12 months postoperatively

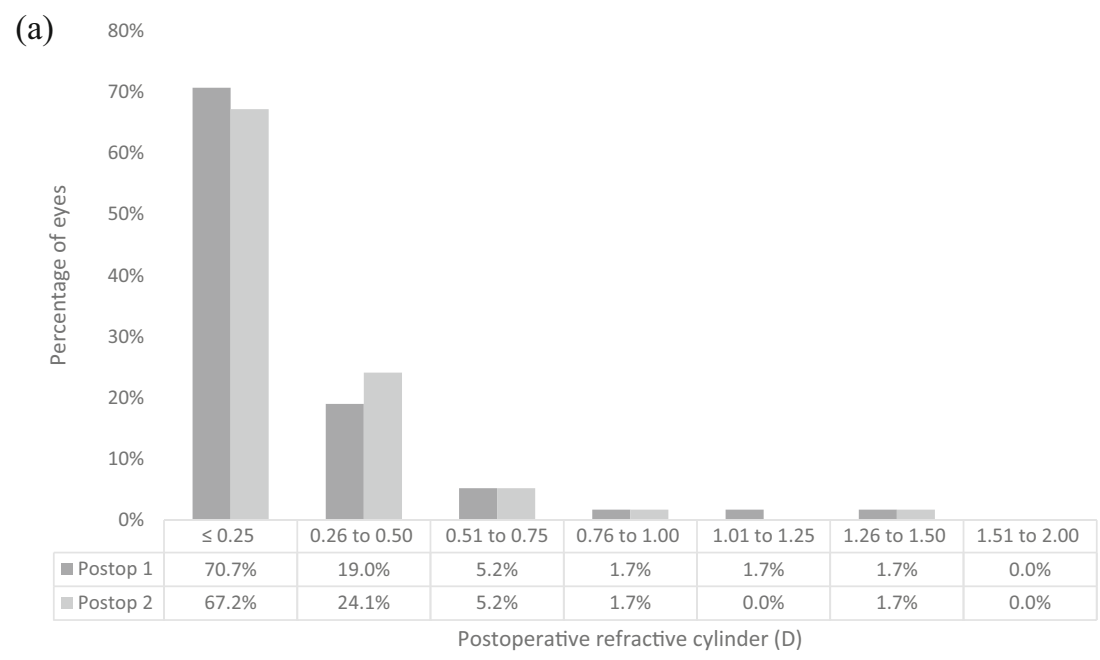

(b)

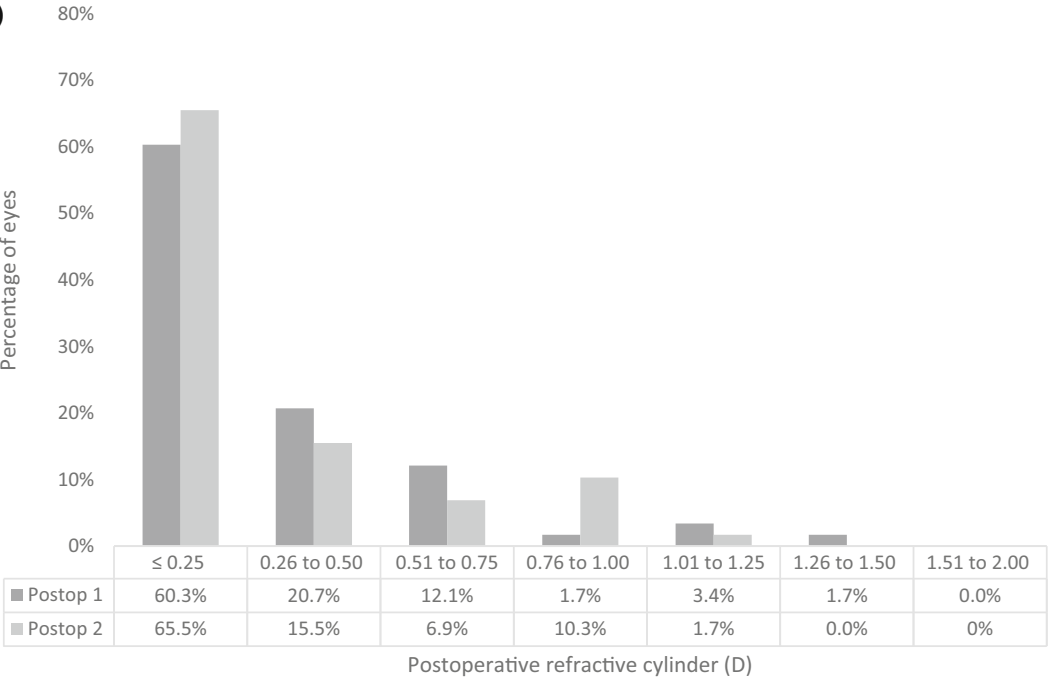

difference does not appear to be clinically significant with only $0.04 \log$ MAR improvement. Furthermore, when patients were asked directly about the quality of their intermediate and near vision, and their ability to perform daily tasks at these distances, there was no significant difference in both the intermediate $(P=0.773)$ and near $(P=0.527)$ vision responses between the two postoperative assessments (Table 4$)$. This study highlights that a range of clear unaided visual acuity is achieved by this implantation methodology and is maintained up to 12 months postoperatively. Furthermore, Fig. 3 displays the defocus curve for this IOL combination, where a peak visual acuity was found in the distance then a gradual decrease to a viewing distance of $50 \mathrm{~cm}$. Visual acuity then appears to remain stable from 50 to $33 \mathrm{~cm}$.

As found in our previous study [7], there is a hyperopic tendency at both postoperative assessments with the EDOF IOL (Fig. 4), which may be due keratometric changes or to the IOL moving posteriorly due to capsular contractions [18, 19], and direct assessment of IOL shift would further help explain the cause. Adjustments have since been made to the biometry A-constants to optimize the postoperative refractive outcomes in our clinic. A study showed that with optical biometry, an improvement of eyes 
Fig. 6 Stability up to 12 months postoperatively plotted as the mean \pm SD of the SE refraction, for both IOL designs

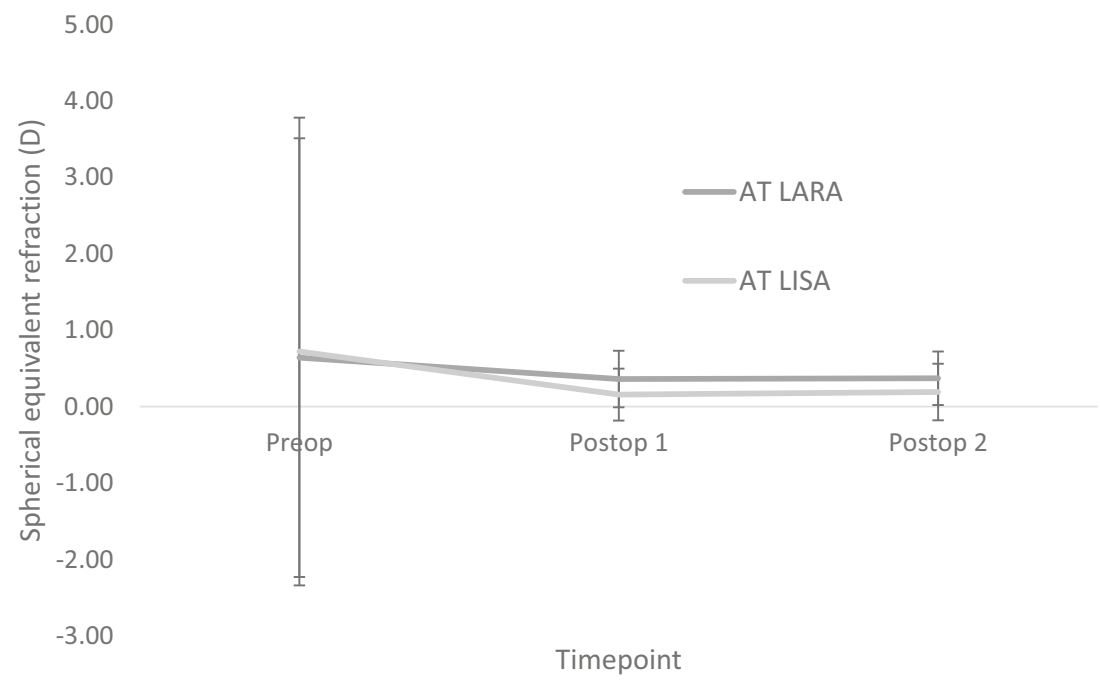

Table 3 Change in refractive error between 1 and 12 months postoperatively for the EDOF IOL and trifocal IOLs

\begin{tabular}{|c|c|c|c|c|c|c|c|}
\hline & $\begin{array}{l}\text { No change SE } \\
\text { (within } \pm 0.25 \text { ) }\end{array}$ & $\begin{array}{l}\% \text { myopic } \\
0.26-0.50\end{array}$ & $\begin{array}{l}\% \text { myopic } \\
0.51-1.00\end{array}$ & $\begin{array}{l}\% \\
\text { myopic }>1.00\end{array}$ & $\begin{array}{l}\% \text { hyperopic } \\
0.26-0.50\end{array}$ & $\begin{array}{l}\% \text { hyperopic } \\
0.51-1.00\end{array}$ & $\begin{array}{l}\% \\
\text { hyperopic }>1.00\end{array}$ \\
\hline $\begin{array}{l}\text { EDOF IOL } \\
\quad(n=58 \\
\text { eyes })\end{array}$ & $75.9(n=44)$ & $6.9(n=4)$ & $6.9(n=4)$ & - & $3.4(n=2)$ & $5.2(n=3)$ & $1.7(\mathrm{n}=1)$ \\
\hline $\begin{array}{l}\text { Trifocal IOL } \\
\quad(n=56 \\
\text { eyes })\end{array}$ & $58.9(n=33)$ & $14.3(n=8)$ & $1.8(n=1)$ & - & $19.6(n=11)$ & $5.4(n=3)$ & - \\
\hline
\end{tabular}

within $\pm 1.00 \mathrm{D}$ of the refractive target was noted when using optimized A-constants [20, 21]. Therefore, optimized A-constants are now utilized in our clinic. However, the difference in refractive outcomes is not significantly different between the postoperative assessments (Table 2) with a good refractive stability outlined in Fig. 6. Most eyes had a mean refractive cylinder of $0.50 \mathrm{D}$ or less (Fig. 5), with no significant difference between the two postoperative assessments. This outlines the high refractive accuracy of both IOL designs and stability over this postoperative period, which is reflected in the high and stable unaided visual acuity outcomes already presented. A further analysis of how the refractive error alters over this time period was attempted in this study, with Table 3 outlining how the refractive error changed with $75.7 \%$ of EDOF eyes and $58.9 \%$ of trifocal eyes showing no change $(<0.25 \mathrm{D})$ in postoperative refractive error. Only 1
EDOF eye showed a change in refractive error of $>1.00 \mathrm{D}$. This further outlines the refractive stability found with these IOLs; however, the difference in changes in refractive error over this time period needs further investigation.

This study also sought to assess QoV, functional vision and overall satisfaction through postoperative questionnaires at both postoperative assessments. Table 4 outlines the responses to the purpose-developed satisfaction questionnaire, where it was reported that $94.9 \%$ and $98.3 \%$ of patients would choose the procedure again or would recommend the procedure at the two respective postoperative assessments. Two patients reported a severe problem at distance at 1 month; however at 12 months they reported only a slight problem. Requirement for reading glasses (Table 4) is similar to that in a study of rotationally asymmetric multifocal IOLs [22]. Functional near and 
Table 4 Comparison of 1-month and 12-month patient experience postoperative data

\begin{tabular}{|c|c|c|c|c|c|}
\hline \multirow{3}{*}{$\begin{array}{l}\text { Postoperative } \\
\text { assessment }\end{array}$} & \multicolumn{5}{|l|}{ Question } \\
\hline & \multicolumn{5}{|c|}{ Compare your vision preoperative to postoperative } \\
\hline & Better & Unchanged & Worse & \multicolumn{2}{|l|}{ Can't remember } \\
\hline Postop 1 & $94.8 \%$ & $3.5 \%$ & $1.7 \%$ & \multicolumn{2}{|l|}{$0 \%$} \\
\hline \multirow[t]{3}{*}{ Postop 2} & $100 \%$ & $0 \%$ & $0 \%$ & $0 \%$ & \\
\hline & \multicolumn{5}{|c|}{ Would you choose this procedure again? } \\
\hline & Yes & No & \multicolumn{3}{|l|}{ Maybe } \\
\hline Postop 1 & $94.9 \%$ & $1.7 \%$ & \multicolumn{3}{|l|}{$3.4 \%$} \\
\hline \multirow[t]{3}{*}{ Postop 2} & $98.3 \%$ & $0 \%$ & $1.7 \%$ & & \\
\hline & \multicolumn{5}{|c|}{ Would you recommend this procedure? } \\
\hline & Yes & No & \multicolumn{3}{|l|}{ Maybe } \\
\hline Postop 1 & $94.9 \%$ & $1.7 \%$ & \multicolumn{3}{|l|}{$3.4 \%$} \\
\hline \multirow[t]{3}{*}{ Postop 2} & $98.3 \%$ & $0 \%$ & $1.7 \%$ & & \\
\hline & \multicolumn{5}{|c|}{ How often do you require reading glasses? } \\
\hline & Never & Occasionally & Quite often & \multicolumn{2}{|l|}{ Always } \\
\hline Postop 1 & $84.5 \%$ & $13.8 \%$ & $1.7 \%$ & \multicolumn{2}{|l|}{$0 \%$} \\
\hline \multirow[t]{3}{*}{ Postop 2} & $86.3 \%$ & $10.3 \%$ & $3.4 \%$ & $0 \%$ & \\
\hline & \multicolumn{5}{|c|}{ How much difficulty do you have doing a regular task that requires you to see well in the distance? } \\
\hline & Distance vision is clear & $\begin{array}{l}\text { Slight } \\
\text { problem }\end{array}$ & Moderate problem & Severe problem & $\begin{array}{c}\text { Intolerable } \\
\text { problem }\end{array}$ \\
\hline Postop 1 & $89.7 \%$ & $6.9 \%$ & $0 \%$ & $3.4 \%$ & $0 \%$ \\
\hline \multirow[t]{3}{*}{ Postop 2} & $89.7 \%$ & $10.3 \%$ & $0 \%$ & $0 \%$ & $0 \%$ \\
\hline & \multicolumn{5}{|c|}{$\begin{array}{l}\text { How much difficulty do you have doing a regular task that requires you to see well at intermediate working } \\
\text { distances? }\end{array}$} \\
\hline & $\begin{array}{l}\text { Intermediate vision is } \\
\text { clear }\end{array}$ & $\begin{array}{l}\text { Slight } \\
\text { problem }\end{array}$ & Moderate problem & Severe problem & $\begin{array}{l}\text { Intolerable } \\
\text { problem }\end{array}$ \\
\hline Postop 1 & $86.2 \%$ & $8.6 \%$ & $5.2 \%$ & $0 \%$ & $0 \%$ \\
\hline \multirow[t]{3}{*}{ Postop 2} & $89.6 \%$ & $5.2 \%$ & $5.2 \%$ & $0 \%$ & $0 \%$ \\
\hline & \multicolumn{5}{|c|}{$\begin{array}{l}\text { How much difficulty do you have doing a regular task that requires you to see well at near working } \\
\text { distances? }\end{array}$} \\
\hline & Near vision is clear & $\begin{array}{l}\text { Slight } \\
\text { problem }\end{array}$ & Moderate problem & Severe problem & $\begin{array}{c}\text { Intolerable } \\
\text { problem }\end{array}$ \\
\hline Postop 1 & $75.9 \%$ & $19.0 \%$ & $3.4 \%$ & $1.7 \%$ & $0 \%$ \\
\hline \multirow[t]{3}{*}{ Postop 2} & $77.6 \%$ & $19.0 \%$ & $3.4 \%$ & $0 \%$ & $0 \%$ \\
\hline & \multicolumn{5}{|c|}{ How were your expectations fulfilled with the procedure? } \\
\hline & More than fulfilled & Fulfilled & $\begin{array}{l}\text { Sufficiently } \\
\text { fulfilled }\end{array}$ & \multicolumn{2}{|l|}{$\begin{array}{l}\text { Not fulfilled at } \\
\text { all }\end{array}$} \\
\hline Postop 1 & $43.1 \%$ & $50.0 \%$ & $5.2 \%$ & \multicolumn{2}{|l|}{$1.7 \%$} \\
\hline Postop 2 & $44.8 \%$ & $48.3 \%$ & $6.9 \%$ & \multicolumn{2}{|l|}{$0 \%$} \\
\hline
\end{tabular}

intermediate vision was excellent (Table 4) with no patients reporting a severe problem or worse at 1 year. Additionally, $93.1 \%$ of patients reported to be more than fulfilled or fulfilled when asked regarding how their expectations were fulfilled with the procedure at both the 1 month and 12 months postoperative assessments. This study appears to show a high satisfaction rating regarding functional vision. The mean overall daytime QoV score at 1 month was $9.12 \pm 0.94$ and $9.24 \pm 0.78$ at 12 months, which is superior to that 
Table 5 Comparison of 1-month and 12-month postoperative visual phenomena data

Visual phenomena calculated on a scale 0 (not at all) to 3 (very). Values represent mean $\pm \mathrm{SD}$ (range); QoV is calculated on a scale 0 (worst) to 10 (best). Values represent mean $\pm \mathrm{SD}$ (range)

\begin{tabular}{llll}
\hline & Postop 1 & Postop 2 & P Value \\
\hline Glare & $0.53 \pm 0.92(0,3)$ & $0.43 \pm 0.75(0,3)$ & .498 \\
Haloes & $0.64 \pm 0.87(0,3)$ & $0.47 \pm 0.68(0,2)$ & .176 \\
Starburst & $0.31 \pm 0.75(0,3)$ & $0.29 \pm 0.62(0,2)$ & .903 \\
Hazy vision & $0.14 \pm 0.44(0,2)$ & $0.03 \pm 0.18(0,1)$ & .063 \\
Blurred vision & $0.16 \pm 0.45(0,2)$ & $0.14 \pm 0.44(0,2)$ & .709 \\
Distortion & $0.02 \pm 0.13(0,1)$ & 0 & .317 \\
Double vision & $0.05 \pm 0.29(0,2)$ & $0.03 \pm 0.26(0,2)$ & .317 \\
Vision Fluctuate & $0.17 \pm 0.42(0,2)$ & $0.21 \pm 0.45(0,2)$ & .317 \\
Depth perception & $0.10 \pm 0.36(0,2)$ & $0.10 \pm 0.36(0,2)$ & 1.000 \\
QoV Day & $9.12 \pm 0.94(7,10)$ & $9.24 \pm 0.78(7,10)$ & .183 \\
QoV Night & $7.88 \pm 1.74(2,10)$ & $8.26 \pm 1.38(5,10)$ & .043 \\
\hline
\end{tabular}

found in other similar studies regarding bilateral implantation of multifocal IOLs [6, 17]. There was no significant difference between the two assessments periods. However, there was a significant improvement in the mean overall night score at 12 months (Table 5). A low incidence of bothersome side effects at both postoperative assessment was reported with most of the visual disturbances reducing at the second assessment; however none were significantly different. It appears that a high QoV and satisfaction is observed from the early postoperative assessment and is maintained within the first year. Patients who reported early postoperative issues improved 12 months postoperatively and were then satisfied with the outcome of the surgery. This study shows that this IOL combination provides high early postoperative satisfaction with a high QoV reported at 1 month, but it does appear that there is further improvement in nighttime QoV as patients may be neuroadapting over this period.

Two trifocal eyes required further laser enhancement. This was performed 11 months post-implantation with one patient to correct a residual refractive error of $+1.50 /-1.25 \times 95$ with the refractive error improving to $+0.25 \mathrm{D}$ post LASIK. The second trifocal eye also received LASIK to treat a residual refractive error of $+1.00 /-0.50 \times 95$ resulting in a post-LASIK refractive error of $0 \mathrm{D}$. Both patients noticed an improvement in their unaided vision. Eight eyes required Nd:YAG capsulotomy, which is significantly lower than a study of multifocal spherical IOLs [23].
In conclusion, this study found that the combined implantation of an EDOF IOL in the dominant eye and a trifocal IOL in the non-dominant eye provides excellent patient satisfaction and provides a range of clear vision up to 12 months postoperatively. A high overall night and day QoV score is reported at both time points, and it appears that neuroadaptation might have occurred between 1 and 12 months postoperatively, resulting in a significantly better overall nighttime QoV score. This study provides the clinician with information regarding combined EDOF and trifocal IOL implantation and how this combination performs up to 12 months postoperatively.

Authors' contribution All authors contributed to the study conception and design. Material preparation, data collection, and analysis were performed by Richard NM, SM, SS, and JEM. The first draft of the manuscript was written by RNM and all authors commented on previous versions of the manuscript. All authors read and approved the final manuscript.

Funding No funds, grants, or other support was received.

Availability of data and material Available upon reasonable request.

Code availability Not applicable.

\section{Declarations}

Conflicts of interest The authors have no relevant financial or non-financial interests to disclose.

Ethical approval This study was performed in line with the principles of the Declaration of Helsinki. Approval was granted 
by the Cathedral Eye Clinic Ethics Committee (Date 12.08.2019/No: CECREC19-08).

Consent to participate Patients gave informed consent for their anonymized data to be used for audit and publication.

Consent for publication Patients gave informed consent for their anonymized data to be used for audit and publication.

Open Access This article is licensed under a Creative Commons Attribution 4.0 International License, which permits use, sharing, adaptation, distribution and reproduction in any medium or format, as long as you give appropriate credit to the original author(s) and the source, provide a link to the Creative Commons licence, and indicate if changes were made. The images or other third party material in this article are included in the article's Creative Commons licence, unless indicated otherwise in a credit line to the material. If material is not included in the article's Creative Commons licence and your intended use is not permitted by statutory regulation or exceeds the permitted use, you will need to obtain permission directly from the copyright holder. To view a copy of this licence, visit http://creativecommons.org/licenses/by/4.0/.

\section{References}

1. Xu Z, Cao D, Chen X, Wu S, Wang X, Wu Q (2017) Comparison of clinical performance between trifocal and bifocal intraocular lenses: a meta-analysis. PLoS ONE 12(10):0186522

2. de Carneros-Llorente AM, de Carneros AM, de CarnerosLlorente PM, Jiménez-Alfaro I (2019) Comparison of visual quality and subjective outcomes among 3 trifocal intraocular lenses and 1 bifocal intraocular lens. J Cataract Refract Surg 45(5):587-594

3. Monaco G, Gari M, Di Censo F, Poscia A, Ruggi G, Scialdone A (2017) Visual performance after bilateral implantation of 2 new presbyopia-correcting intraocular lenses: trifocal versus extended range of vision. J Cataract Refract Surg 43(6):737-747

4. Marques EF, Ferreira TB (2015) Comparison of visual outcomes of 2 diffractive trifocal intraocular lenses. J Cataract Refract Surg 41(2):354-363

5. Shen Z, Lin Y, Zhu Y, Liu X, Yan J, Yao K (2017) Clinical comparison of patient outcomes following implantation of trifocal or bifocal intraocular lenses: a systematic review and meta-analysis. Sci Rep 7(1):1-9

6. McNeely RN, Pazo E, Spence A, Richoz O, Nesbit MA, Moore TC, Moore JE (2017) Visual quality and performance comparison between 2 refractive rotationally asymmetric multifocal intraocular lenses. J Cataract Refract Surg 43(8):1020-1026

7. McNeely RN, Moutari S, Palme C, Moore JE (2020) Visual outcomes and subjective experience after combined implantation of extended depth of focus and trifocal IOLs. J Refract Surg 36(5):326-333

8. De Vries NE, Webers CA, Touwslager WR, Bauer NJ, de Brabander J, Berendschot TT, Nuijts RM (2011)
Dissatisfaction after implantation of multifocal intraocular lenses. J Cataract Refract Surg 37(5):859-865

9. Woodward MA, Randleman JB, Stulting RD (2009) Dissatisfaction after multifocal intraocular lens implantation. J Cataract Refract Surg 35(6):992-997

10. Shekhar S, Sureka SP, Sahu SK (2015) Multifocal intraocular lens explantation: a case series of 50 eyes. Am J Ophthalmol 159(1):202

11. Schallhorn SC, Teenan D, Venter JA, Hannan SJ, Schallhorn JM (2019) Initial clinical outcomes of a new extended depth of focus intraocular lens. J Refract Surg 35(7):426-433

12. Tarib I, Kasier I, Herbers C, Hagen P, Breyer D, Kaymak H, Klabe K, Lucchesi R, Teisch S, Diakonis VF, Hahn U (2019) Comparison of visual outcomes and patient satisfaction after bilateral implantation of an EDOF IOL and a mix-and-match approach. J Refract Surg 35(7):408-416

13. Mendicute J, Kapp A, Levy P, Krommes G, Arias-Puente A, Tomalla M, Barraquer E, Rozot P, Bouchut P (2016) Evaluation of visual outcomes and patient satisfaction after implantation of a diffractive trifocal intraocular lens. J Cataract Refract Surg 42(2):203-210

14. Venter JA, Barclay D, Pelouskova M, Bull CE (2014) Initial experience with a new refractive rotationally asymmetric multifocal intraocular lens. J Refract Surg 30(11):770-776

15. Mojzis $P$, Peña-García P, Liehneova I, Ziak P, Alió JL (2014) Outcomes of a new diffractive trifocal intraocular lens. J Cataract Refract Surg 40(1):60-69

16. Schallhorn SC, Hettinger KA, Teenan D, Venter JA, Hannan SJ, Schallhorn JM (2020) Predictors of patient satisfaction after refractive lens exchange with an extended depth of focus IOL. J Refract Surg 36(3):175-184

17. McNeely RN, Pazo E, Spence A, Richoz O, Nesbit MA, Moore TC, Moore JE (2017) Visual outcomes and patient satisfaction 3 and 12 months after implantation of a refractive rotationally asymmetric multifocal intraocular lens. J Cataract Refract Surg 43(5):633-638

18. Wallace HB, Misra SL, Li SS, McKelvie J (2018) Predicting pseudophakic refractive error: Interplay of biometry prediction error, anterior chamber depth, and changes in corneal curvature. J Cataract Refract Surg 44(9):1123-1129

19. Nistad K, Göransson F, Støle E, Shams H, Gjerdrum B (2017) The use of capsular tension rings to reduce refractive shift in patients with implantation of trifocal intraocular lenses. J Refract Surg 33(12):802-806

20. Aristodemou P, Cartwright NEK, Sparrow JM, Johnston RL (2011) Intraocular lens formula constant optimization and partial coherence interferometry biometry: refractive outcomes in 8108 eyes after cataract surgery. J Cataract Refract Surg 37(1):50-62

21. Nemeth G, Nagy A, Berta A, Modis L (2012) Comparison of intraocular lens power prediction using immersion ultrasound and optical biometry with and without formula optimization. Graefes Arch Clin Exp Ophthalmol 250(9):1321-1325

22. Muñoz G, Albarrán-Diego C, Ferrer-Blasco T, Sakla HF, García-Lázaro S (2011) Visual function after bilateral implantation of a new zonal refractive aspheric multifocal intraocular lens. J Cataract Refract Surg 37(11):2043-2052

23. Biber JM, Sandoval HP, Trivedi RH, de Castro LEF, French JW, Solomon KD (2009) Comparison of the incidence and 
visual significance of posterior capsule opacification between multifocal spherical, monofocal spherical, and monofocal aspheric intraocular lenses. J Cataract Refract Surg 35(7):1234-1238
Publisher's Note Springer Nature remains neutral with regard to jurisdictional claims in published maps and institutional affiliations. 